\title{
"Evaluating the Structural Validity of the Multifactor Leadership Questionnaire (MLQ), Capturing the Leadership Factors of Transformational-Transactional Leadership
}

\author{
Nuttawuth Muenjohn \\ School of Management, RMIT University \\ E-Mail: nuttawuth.muenjohn@rmit.edu.au \\ Anona Armstrong \\ Victoria University \\ E-Mail: anona.armstrong@vu.edu.au
}

\begin{abstract}
Most previous research on transformational leadership involved the use of the "Multifactor Leadership Questionnaire" (MLQ) to measure various aspects of transformational-transactional leadership. Although the MLQ is widely used, the instrument has been criticized in some areas of its measurement factors. In this study, three proposed models were tested by Confirmatory Factor Analysis (CFA) using the multi-data source of 138 cases. Results revealed that the overall fit of the nine-correlated factor model, on its second test, was statistically significant and that indicated that the Full Leadership Model (nine-correlated leadership model) could be the most appropriately and adequately capturing the factor constructs of transformationaltransactional leadership.
\end{abstract}

Keywords: Transformational Leadership, Structural Validity, Multifactor Leadership Questionnaire, Confirmatory Factor Analysis

\footnotetext{
* Acknowledgement: The authors would like to thank the Centre for International Corporate Governance Research (CICGR), Faculty of Business \& Law, Victoria University, Australia and Faculty of Business, Asian University, Thailand for their support of this work.
} 


\section{INTROUDUCTION}

Although the constructs of transformational leadership model are not relatively new and could be found in the works of earlier management theorists (Humphreys and Einstein, 2003), Bass' (1985) transformational leadership is considered to be one of the leadership theories that have captured many leadership scholars' attentions more than twenty years. Based on Burns' work (1978), Bass \& Avolio (1997) proposed three majors leadership behaviours, transformational leadership, transactional leadership, and laissezfaire leadership behaviours respectively. Transformational leadership, according to Bass (1985), is defined as a process in which a leader tried to increase followers' awareness of what was right and important and to motivate followers to perform "beyond expectation". Bass \& Avolio (1997) indicated that transformational leaders usually display their behaviours associate with four characteristics as follow:

Idealised Influence is described when a leader is being a role model for his/her followers and encouraging the followers to share common visions and goals by providing a clear vision and a strong sense of purpose. Inspirational Motivation represents behaviours when a leader tries to express the importance of desired goals in simple ways, communicates high level of expectations and provides followers with work that is meaningful and challenging. Intellectual Stimulation refers to leaders who challenge their followers' ideas and values for solving problems. Individualised Consideration refers to leaders who spend more time teaching and coaching followers by treating followers based on individual basic.

In contrast to transformational leadership, transactional leadership was mainly based on contingent reinforcement. Three components of transactional leadership were identified. Contingent Reward refers to an exchange of rewards between leaders and followers in which effort is rewarded by providing rewards for good performance or threats and disciplines for poor performance. The leader who relies heavily on Management-by-Exception (Passive) intervenes with his or her group only when procedures and standards for accomplishing tasks are not met. In contrast, Managementby-Exception (Active) leaders are characterised as monitors who detect mistakes. The last leadership behaviour is Laissez-faire or non-leadership that exhibits when leaders avoid clarifying expectations, addressing conflicts, and making decision.

Transformational leaders were on average more highly positively correlated with their subordinates' satisfaction, extra effort, and effectiveness when compared with transactional and laissez-faire leaders and thus described by different authors to have a 
high relationship with leadership success (see e.g. Kirkbride, 2006; Ingram, 1997; Medley and Larochelle, 1995).

The aim of this study was to examine the structural validity of the "Multifactor Leadership Questionnaire" (MLQ From 5x) developed by Bass and Avolio (1997). Confirmatory Factor Analysis (CFA), employing the Analysis of Moment Structures (AMOS; Arbuckle, 1997), was conducted by using the multi-data source of 138 cases obtained from leaders themselves and their direct-report subordinates.

\section{MLQ: ITS TESTS AND REVIEWS}

The MLQ (5x) contained 45 items tapping nine conceptually distinct leadership factors and three leadership outcomes. Five scales were identified as characteristic of transformational leadership (Idealized influence attributed and behaviour, Inspirational motivation, Individual consideration, and Intellectual stimulation). Three scales were defined as characteristic of transactional leadership (Contingent reward, Management-byexception-active, and Management-by-exception-passive). One scale was described as non-leadership (Laissez-faire).

Although the MLQ is the most widely used instrument to assess transformational leadership theory (Kirkbride, 2006) and "is considered the best validated measure of transformational and transactional leadership" (Ozaralli, 2003, p. 338), the MLQ had been criticized in some areas for its conceptual framework (see e.g. Charbonneau, 2004, Yukl, 1998; Northouse, 1997).

According to Tepper and Percy (1994, p. 735), the most immediate concern regarding the MLQ was its structural validity. Kelloway, Barling, and Helleur (2000), for example, found strong correlations among the subcomponents of transformational leadership. Yammarino and Dubinsky (1994) also reported very high correlations among the four transformational factors and very high loadings of the items on a single transformational scale from the data of 105 salespersons and their 33 sales supervisors. Similar results were reported by the study of Tracey and Hinkin (1998) when they tested the contractual distinction of the four transformational factors. However, Den Hartog, Van muijen, and Koopman (1997) discovered mixed results when the distinction between the three-factor solution was found in their study (transformational, transactional and laissez-faire) but, at the subscale level, passive management-by-exception and laissezfaire belonged to one factor. 
Another study that focused on the measurement qualities of the MLQ was conducted by Tepper and Percy (1994). Tepper and Percy examined the MLQ's latent structure using confirmatory analyses at the item and scale levels with two independent samples. In the first sample, the results suggested that none of the models obtained a particularly good fit to the data. In the second sample, Tepper and Percy only focus on the convergent and discriminant validity of the dimensions underlying the idealized influence, inspirational motivation, and contingent reward constructs. Similar to the findings of the first sample, the results indicated that the idealized influence and inspirational motivation scales converged to form a single latent construct and thus they argued that both scales should be treated as indicators of a single underlying dimension.

More recently, after testing three hierarchical models, Carless (1998) concluded that "the MLQ (Form-5X) does not measure separate transformational leader behaviours, instead, it appears to assess a single, hierarchical construct of transformational leadership" (p. 357). Similarly, Densten and Sarros (1997) investigated the structure of transformational leadership using a higher-order confirmatory factor analysis and found that the four second-order transformational factors (II, IM, IS, and IC) were confirmed by their data and thus argued that the structure of the MLQ seemed to be more complex than its original representation.

Given the extensive review above, it appears that: (a) the transformational four factors were highly correlated with each other and thus researchers argued that the four factors might be best represented as a single transformational leadership scale (e.g. Yammarino and Dubinsky, 1994; Tracey and Hinkin, 1998; Carless, 1998); (b) in particular, the conceptual distinction between the idealized influence and inspirational motivation factors had not been clearly articulated (e.g. Tepper and Percy, 1994), and (c) the passive forms of leadership were also troublesome, in other words, there was an unclear distinction between the management-by-exception (passive) and laissez-faire factors (Den Hartog et al., 1997). In other words, the unclear factor structure of the MLQ found in previous research raised doubts about evaluating leadership behaviours as measured by the MLQ. Consequently, the underlying structure of the MLQ, particularly the latest version of the MLQ (5X), should be further examined.

\section{THREE FACTOR MODELS TESTED}

In this study, the sample size consisted of 138 cases obtained from combining the data from two separate samples ( $N 47$ and $N 91)$. The multi-data source was used in order 
to: (a) avoid a single-source bias (Tracey and Hinkin, 1998), and (b) increase the size of sample. The new sample size of 138 cases is considered as a 'small to moderate sample size' (Bollen, 1989, p. 262). However, Bryant and Yarnold (1995) warned that if the separate samples showed significant mean difference across the indicators, combining the raw data from these different groups could produce spurious correlations for the pooled sample. Bryant and Yarnold (1995), therefore, suggested 'Before pooling the data from separate groups, researchers should first standardize the raw data separately within each group and then pool these data' (p. 119). Consequently, the standardized processing of the raw data was conducted separately before combining the data from both samples in this study.

Three factor models were tested in this study. First, one general factor model (global leadership) in which all items load on the same factor. Second, a three correlated factor model (transformational, transactional, and non-leadership) in which the 20 items measuring transformational leadership load on the first factor, the 12 items measuring transactional leadership load on the second factor, and the 4 items measuring laissez-faire load on the third factor. Third, a nine correlated factor model (full rang leadership model) in which the items measuring each leadership dimension load on nine separate factors.

\section{CONFIRMATORY FACTOR ANALYSIS (CFA)}

Since previous researches examining the structure of the MLQ provided mixed results, either positive or negative, confirmatory factor analysis was conducted to measure whether the data from this study confirm the structural validity of the latest version of the MLQ.

A primary goal of Confirmatory Factor Analysis (CFA) is to evaluate the factor structure within a measurement model and to determine how well the measurement model fits to its data (Bollen, 1989). Within CFA model, each measure in a data set is considered to be an observed indicator of one or more underlying latent constructs. The CFA model assumes that there are two sources of variation in responses to observed indicators. That is, observed indicators are assumed to be influenced by latent underlying factors and by unique measurement error (e.g. the influence of unmeasured variables). Unlike Exploratory Factor Analysis (EFA), in CFA, one or more models are built and the prediction of the interrelationships between the latent and observed variables within the model is given before the analysis.

The difference between each of these predicted interrelationships and the actual 
interrelationships is referred to as a "fitted residual". To evaluate how well the model fits its data, the value of the fitted residual (refers to "goodness of fit") in the particular model is assessed. The closer these residuals are to zero, the better the model fits the data.

The relative fit of a proposed model can be assessed by using different goodness of fit indices. For example, the ratio of chi-square to degrees of freedom $\left(\chi^{2} / \mathrm{df}\right)$ (Hoelter, 1983), as this ratio decreases and approaches zero, the fit of the model improves. In particular, the values of 3.00 or less indicated an adequate fit (Byrne, 1989). Also, the root mean square error of approximation (RMSEA) is another fit index often used to evaluate a given model. Brown and Cudeck (1993) suggested that the RMSEA value of .05 or less indicated a close fit between data and the model. Joreskog and Sorbom's (1989) goodness of fit index (GFI) and the adjusted goodness of fit index (AGFI) are also usually adopted when conducting CFA. The values greater than 0.9 for GFI and greater than 0.8 for AGFI indicate a good fit of the model.

One of major concerns when conducting CFA is the effect of the sample size on the goodness of fit indices. According to Bryant and Yarnold (1995), the chi-square statistic is sensitive to sample size and thus small samples may provide less power to detect a model's true lack of fit. In this regard, Bentler (1985) guided an appropriate sample size by comparing the number of subjects per estimated parameter. However, it should be noted that there are no definitive recommendations when it comes to the adequate sample size to obtain reliable results (see Bentler and Chou, 1987; Bryant and Yarnold, 1995; Tabachnick and Fidell, 1996; Arbuckle, 1997; Gerbling and Anderson, 1985; Bryman and Cramer, 1990). Since there is no clear agreement on the appropriate sample size, Pillai, Scandura, and Williams (1999) suggested that a range of fit indices, such as chisquare (dependent on sample size) and GFI (independent of sample size), should be taken into account.

\section{RESULTS}

A reliability check for the MLQs (English and Thai versions) were conducted to provide evidence that the MLQ, especially after translating from English to Thai, produced the data for which it was designed. The Cronbach alpha produced, alpha $=0.86$ for the original MLQ and alpha $=0.87$ for the translated MLQ, the reliability values were greater than 0.70 indicating an acceptable statistic testing level (Nunnally, 1967).

To examine the construct validity of the MLQ (5X), confirmatory factor analysis was performed with AMOS using the maximum likelihood estimation method. Based on 
the results of the first analysis (Table 1), it is suggested that none of the models obtained a particularly good fit to the data.

Table 1 Comparison of overall fit measures among the three separate factor models

\begin{tabular}{lcccccc}
\hline Model & $\mathbf{X}^{\mathbf{2}}$ & $\mathbf{d f}$ & $\mathbf{x}^{\mathbf{2}} / \mathbf{d f}$ & GFI & AGFI & RMSEA \\
\hline First Analysis & & & & & & \\
\hline One factor model & 1271.21 & 594 & 2.14 & .65 & .60 & .09 \\
Three factor model & 1228.65 & 591 & 2.08 & .66 & .62 & .08 \\
Nine factor model & 1060.99 & 558 & 1.90 & .71 & .65 & .08 \\
\hline Second Analysis & $\mathbf{X}^{\mathbf{2}}$ & $\mathbf{d f}$ & $\mathbf{x}^{\mathbf{2}} / \mathbf{d f}$ & $\mathbf{G F I}$ & AGFI & RMSEA \\
\hline One factor model & 916.85 & 570 & 1.61 & .73 & .69 & .06 \\
Three factor model & 924.62 & 569 & 1.62 & .74 & .69 & .07 \\
Nine factor model & 540.18 & 474 & 1.14 & .84 & .78 & .03 \\
\hline
\end{tabular}

Note: All models were significant at $\mathrm{p}<.01$.

However, Modification Indices (MI) provided by AMOS (Analysis of Moment Structures: Arbuckle, 1997) suggested that the fit of the tested models could be improved by correlating selected parameters within the models. This modified strategy was used in this study because it helped to increase the overall structural validity without any changes to the original factor models and that was consistent with the primary interest of the current study. The results from the second analysis indicated that all of the fit measures and the chi-square tests improved as the model progressed from a one-factor model to a nine-factor model (Table 1).

In particular, the overall chi-square of the nine factor model was statistically significant $\left(x^{2}=540.18 ; d f=474 ; \mathrm{p}<.01\right)$, the ratio of the chi-square to the degrees of freedom $\left(x^{2} / d f\right)$ was 1.14 , the root mean square error of approximation (RMSEA) was 0.03 , the goodness of fit index (GFI) was .84 , and the adjusted goodness of fit index (AGFI) was .78. Therefore, by taking all the fit indices into account and comparing them with the results of previous studies, it might be said that the nine-factor model could be regarded as a "reasonable fit" to the data in this study (See e.g. Bycio et al., 1995).

\section{DISCUSSION}

The results of the confirmatory factor analyses at the item level demonstrated that 
the nine-factor model was the best reflection of the data in the current study when compared with two other models.

These findings could imply that: (a) the nine factor model appeared to be the best theoretical construct representing the latest form of the MLQ whether it was tested with the large sample in the Bass and Avolio study $(\mathrm{n}=1,394)$ or small sample in the current study ( $\mathrm{n}=138$ ); and (b) although some leadership factors were highly correlated with each other, such as among the five factors of transformational leadership, these factors still distinctly measured their own leadership constructs. This implication could be seen when combined the leadership factors into a single factor model (global leadership model), and three-factor model (transformational, transactional, and non-leadership model), the results of overall fit was lower than the nine-factor model (full leadership model).

While previous research provided diverse results (e.g. Tepper and Percy, 1994; Yammarino and Dubinsky, 1994; Tracey and Hinkin, 1998; Bycio et al., 1995), the current study was distinct itself from the previous ones. Firstly, some of previous studies used only a subset of the total items (Bycio et al., 1995; Tepper and Percy, 1994; Den Hartog et al., 1997) and, according to Himkin and Tracey (1999), provided an inadequate justification. Secondly, most studies targeted only the transformational factors rather than full range of leadership model (nine leadership model). Thirdly, those studies employed different versions of the MLQ that contained a number of different items. Lastly, the current study used the latest versions of the MLQ.

In summary, after acknowledging the MLQ criticisms by refining several versions of the instruments, the version of the MLQ, Form 5X (Bass and Avolio, 1997), is successful in adequately capturing the full leadership factor constructs of transformational leadership theory. Therefore, this should provide researchers with confidence, to some certain extent, in using the MLQ 5x version to measure the nine leadership factors representing transformational, transactional, and non-leadership behaviours.

\section{REFERENCES}

Arbuckle, J. L. 1997. Amos user's guide: version 3.6, Chicago, SmallWaters Corp.

Bass, B. M. 1985. Leadership and Performance beyond expectations, New York, Free Press.

Bass, B. M. and Avolio, B. J. 1997. Full range leadership development: Manual for the multifactor leadership questionnaire, CA, Mind Garden. 
Bentler, P. M. 1985. Theory and implementation of EQS: A structural equations program, Los Angeles: BMDP Statistical Software.

Bentler, P. M. and Chou, C. 1987. 'Practical issues in structural model modeling', Sociological Methods and Research, Vol. 16, 78-117.

Bollen, K. A. 1989. Structural equations with latent variables, New York, John Wiley \& SONS.

Brown, M. W. and Cudeck, R. 1993. 'Alternative ways of assessing model fit', In K. A. Bollen and J. S. Long (eds.), Testing structural equation models, Newbury Park, CA, Sage, 136-162.

Bryant, F. B. and Yarnold, P. R. 1995. 'Principal-components analysis and exploratory and confirmatory factor analysis', In L. G. Grimm and P. R. Yarnold (eds.), Reading and understanding multivariate statistics, Washington DC, American Psychological Association, 99-136.

Bryman, A. and Cramer, D. 1990. Quantitative data analysis for social scientists, London, Routledge.

Burns, J. M. 1978. Leadership, New York, Harper \& Row.

Bycio, P., Hackett, R. D., and Allen, J. S. 1995. 'Further assessments of Bass's (1985) conceptualization of transformational and transactional leadership', Journal of Applied Psychology, Vol. 80, No. 4, 468-478.

Byrne, B. M. 1989. A primer of LISREL: Basic applications and programming for confirmatory factor analytic models, New York, Springer-Verlag.

Carless, S. A. 1998. 'Assessing the discriminate validity of transformational leadership behavior as measured by the MLQ', Journal of Occupational and Organizational Psychology, 71, 353-358.

Charbonneau, D. 2004. 'Influence tactics and perceptions of transformational leadership', The Leadership \& Organizational Development Journal, Vol. 25, No. 7, pp. 565576.

Den Hartog, D. N., Van Muijen, J. and Koopman, P. 1997. 'Transactional versus transformational leadership: An analysis of the MLQ', Journal of Occupational and Organizational Psychology, Vol. 70, Part 1, 19-34.

Densten, I. and Sarros, J. 1997. Re-thinking transformational leadership factors, working paper 59/97, July, Monash University.

Gerbling, D. W. and Anderson, J. C. 1985. 'The effects of sampling error and model characteristics on parameter estimation for maximum likelihood confirmatory factor 
analysis', Multivariate Behavioural Research, Vol. 20, 255-271.

Hinkin, T. R. and Tracey, J. B. 1999. 'The relevance of charisma for transformational leadership in stable organization', Journal of Organizational Change Management, Vol. 12, No. 2, 105-119.

Hoelter, J. W. 1983. 'The analysis of covariance structures: Goodness of fit indices', Sociological Methods and Research, 11, 325-344.

Humphreys, J. H. and Einstein, W. O. 2003. 'Nothing new under the sun: transformational leadership from a historical perspective', Management Decision, Vol. 41, No. 1, pp. 85-95.

Ingram, P. D. 1997. 'Leadership behaviours of principals in inclusive educational settings', Journal of Educational, Vol. 35, Issue 5, 411-427.

Joreskog, K. G. and Sorbom, D. 1989. LISREL-7 user's reference guide, Mooresville, IN, Scientific Software.

Kelloway, E. K., Barling, J. and Helleur, J. 2000. 'Enhancing transformational leadership: the roles of training and feedback', Leadership \& Organization Development Journal, Vol. 21, No. 3, pp. 145-149.

Kirkbride, P. 2006. 'Developing transformational leaders: the full range leadership model in action', Industrial and Commercial Training, Vol. 38, No. 1 pp.23-32.

Medley, F. and Larochelle, D. R. 1995. 'Transformational leadership and job satisfaction', Nursing Management, Vol. 26, No. 9, 64-69.

Northouse, P. G. 1997. Leadership: Theory and Practice, California, Sage Publications.

Nunnally, J. 1967. Psychometric Theory, New York, McGraw-Hill.

Ozaralli, N. 2003. 'Effects of transformational leadership on empowerment and team effectiveness', Leadership \& Organization Development Journal, Vol. 24, No. 6, pp 335-344.

Pillai, R., Scandura, T. A., and Williams, E. A. 1999. 'Leadership and organizational justice: Similarities and differences across cultures', Journal of International Business Studies, Vol. 30, No. 4, 763-779.

Tabachnick, B. G. and Fidell, L. S. 1996. Using multivariate statistics, third edition, New York, Harper Colloins.

Tepper, B. J. and Percy, P. M. 1994. 'Structural validity of the Multifactor Leadership Questionnaire', Educational and Psychological Measurement, Vol. 54, No. 3, 734744.

Tracey, J. B. and Hinkin, T. R. 1998. 'Transformational leadership or effective 
management practices?', Group and Organization Management, Vol. 23, No. 3, 220236.

Yammarino, F. and Dubinsky, A. 1994. 'Transformational leadership theory: Using levels of analysis to determine boundary conditions', Personal Psychology, Vol. 47, No. 4, 787-811.

Yukl, G. 1998. Leadership in Organizations, Fourth edition, New Jersey, Prentice Hall. 
